\title{
The Significance of MicroRNA-449a and Its Potential Target HDAC1 in Patients With Colorectal Cancer
}

\author{
DAICHI ISHIKAWA ${ }^{1}$, CHIE TAKASU ${ }^{1}$, HIDEYA KASHIHARA ${ }^{1}$, MASAAKI NISHI ${ }^{1}$, TAKUYA TOKUNAGA ${ }^{1}$, \\ JUN HIGASHIJIMA $^{1}$, KOZO YOSHIKAWA ${ }^{1}$, KOJI YASUTOMO ${ }^{2}$ and MITSUO SHIMADA ${ }^{1}$ \\ ${ }^{1}$ Department of Surgery, The University of Tokushima, Tokushima, Japan; \\ ${ }^{2}$ Department of Immunology and Parasitology, The University of Tokushima, Tokushima, Japan
}

\begin{abstract}
Background: In a previous study, we demonstrated that deficiency of microRNA-449a (miR-449a) promoted colorectal tumorigenesis. In this study, the significance of miR$449 a$ in the prognosis and relationship with HDACl in colorectal cancer was examined. Materials and Methods: Seventy-two patients with colorectal cancer and 16 patients with colorectal liver metastasis who underwent surgery were included. miR-449a expression in tumor tissue of resected specimen was investigated by real-time polymerase chain reaction and histone deacetylase 1 (HDAC1) expression was examined by immunohistochemistry. Results: Lymphovascular invasion and increased serum carcinoembryonic antigen levels were seen more frequent in patients with low miR-449a expression. Patients with low miR-449a expression were found to have a poorer prognosis than those with high expression. Vascular invasion, increased serum carbohydrate antigen 19-9 level and low miR-449a were associated with poorer diseasefree survival. miR-449a expression was lower in metastatic liver tumor compared to primary tumor. HDACl positivity was higher in patients with low miR-449a. Conclusion: miR-449a level might be a prognostic indicator for colorectal cancer and miR-449a might regulate HDAC1 expression.
\end{abstract}

MicroRNAs (miRNAs) are non-coding RNAs of 21-25 nucleotides that regulate gene expression by targeting the 3untranslated regions (UTRs) of mRNAs, which result in miRNA degradation or inhibition of miRNA translation (1, 2). miRNAs are considered to regulate various cell physiological processes, including development, proliferation,

Correspondence to: Daichi Ishikawa, MD, Ph.D., Department of Surgery, The University of Tokushima, 3-18-15 Kuramoto, Tokushima City, Tokushima, 770-8503, Japan. Tel: +81886337137 , Fax: +81 886319698, e-mail: daichi-19850125@ hotmail.co.jp

Key Words: Colorectal cancer, microRNAs, microRNA-449a, $m i R-449 a$, histone deacetylase 1 , HDAC1, colorectal liver metastasis, CRLM. differentiation and apoptosis (3). Recently aberrantly expressed miRNAs were reported to be involved in tumorigenesis, as oncogenes or tumor suppressors $(4,5)$. miRNA-34a-5p suppresses colorectal cancer (CRC) metastasis, and its expression predicts recurrence in patients with stage II/III CRC (6). Thus, miRNAs may be used as prognostic indicators and potential targets for cancer therapy.

The miR-449 cluster contains sequences and secondary structures similar to those of the miR-34 family. Therefore, they have been classified as a single family of miRNAs. The expression of $m i R-449 a$ is reduced in several cancer types, such as gastric and bladder cancer (3). Furthermore, $m i R$ $449 a$ regulates several genes associated with tumorigenesis, including the gene encoding c-MYC, histone deacetylase (HDAC) (7-10) and cell division cycle 25 homolog A (CDC25A), suggesting that $m i R-449 a$ may have oncogenic effects. A previous study succeeded in the creation of a $m i R$ $449 a$-deficient mouse and demonstrated that deficiency of $m i R-449 a$ promoted azoxymethane and dextran sodium sulfate-induced colorectal tumorigenesis (11). miR-449adeficient mice showed a higher expression of Ki-67 compared to wild-type mice, suggesting that normal colorectal mucosa has a more proliferative phenotype. The study also demonstrated that the expression level of $m i R$ $449 a$ inversely correlated with pathological malignancy and was related to disease-free survival in patients.

HDAC1 plays an important role in the expression of various genes through chromatin remodeling. The aberrant activation of HDAC1 in tumor cells leads to diverse transcriptional repression of genes mainly involved in the regulation of differentiation, angiogenesis, proliferation, migration and metastasis. A number of studies have reported the potential relevance of HDAC1 in various malignant tumors (12). It has been demonstrated that positive expression of HDAC1 was a prognostic indicator of intrahepatic cholangiocarcinoma (13). From the Targetscan7.0 database (http://www.targetscan.org/ vert_72), HDAC1 mRNA was strongly inhibited or downregulated by $m i R-449 a$ as a potential target gene according to the matched basal sequence. 
The aim of this study was to investigate the significance of $m i R-449 a$ in the clinical setting and to examine the relationship of $m i R-449 a$ with HDAC1, which is a potential target of $m i R-449 a$, in primary colorectal tumor samples.

\section{Materials and Methods}

Patients and tissue samples. This study was approved by the Ethics Committee of the Tokushima University Hospital (approval number: 29001) and the patient information was obtained from their medical records. From 72 patients, a total of 72 samples of primary CRC and 16 samples of colorectal liver metastasis (CRLM) were investigated in this study. All the samples that were surgically completely resected were included, whereas samples with apparent remaining tumor or residual malignant cells on the resected margin were excluded. The CRCs were surgically resected at the Tokushima University Hospital from 2008 to 2013 and the CRLMs were also resected from 2008 to 2013. Post-operatively, the patients were followed-up using the serum levels of serum carcinoembryonic antigen (CEA) and serum carbohydrate antigen 19-9 (CA19-9), and computed tomography every 3 months to diagnose recurrence of the disease. The 5-year overall survival (OS) and disease-free survival (DFS) rates after surgery were investigated. Prognostic factors including age, gender, location of the tumor, differentiation, lymph node metastasis, lymphovascular invasion, serum tumor markers and the expression level of $m i R-449 a$ in the tumor were univariately and multivariately analyzed.

Immunohistochemistry. Tissue specimens were fixed in $10 \%$ formaldehyde, embedded in paraffin, and cut into 4- $\mu$ m-thick sections. Immunohistochemistry was performed as reported previously (14). Briefly, sections were deparaffinized with xylene, followed by rehydration in a graded ethanol series. The sections were treated with $3 \%$ hydrogen peroxide in methanol for 10 minutes to quench endogenous peroxidase activity. Antigen retrieval was performed by boiling in $10 \mathrm{mM}$ citrate buffer $(\mathrm{pH} \mathrm{6)}$. After incubation with $1 \%$ blocking solution (Blocking One Histo; Nakarai Tesque, Kyoto, Japan) to block nonspecific antibody boiling, the sections were incubated with a primary antibody against HDAC1 (1:100, SC-7872; Santa Cruz, Dallas, TX, USA) for $60 \mathrm{~min}$ at room temperature. After washing with phosphate-buffered saline, the sections were subjected to the Dako REAL EnVision/HRP detection system (Dako Corporation, Tokyo, Japan) for $60 \mathrm{~min}$ at room temperature. The peroxidase reaction was developed with 3,3'-diaminobenzidine as the chromogen. The sections were counterstained with Mayer's hematoxylin, dehydrated in a graded series of ethanol, treated with xylene, and mounted in a synthetic resin. Immunostaining was evaluated by a pathologist without knowledge of the clinical data. HDAC1 expression was scored by the intensity of staining $(0$, negative; 1 , weak; 2 , moderate; 3 , intense) and proportion of positively stained cells. The intensity score was multiplied by the percentage of positively stained cells and used in evaluation. A score of more than 90 was regarded as positive (Figure 1). The samples were evaluated in five different fields at $\times 400$, and at least 1,000 tumor cells were analyzed in each sample.

miRNA expression analyses. Total RNA including non-coding small RNA such as microRNA was isolated using the miRNeasy Kit (Qiagen, Hilden, Germany) following the manufacturer's instructions. Reverse transcription was carried out with TaqMan ${ }^{\circledR}$ MicroRNA Reverse Transcription kit (Thermo Fisher Scientific, Walthan, MA, USA). For single miRNA assays, $25 \mathrm{ng}$ of total RNA was reverse transcribed with sequence-specific primers. For each quantitative polymerase chain reaction (qPCR), 5-10 ng of the initial total RNA was used from cDNA samples. Every sample was amplified as triplicate using specific primer pairs or TaqMan ${ }^{\circledR}$ assays using the GoTaq ${ }^{\circledR}$ master mix (Promega, Mannheim, Germany) or TaqMan ${ }^{\circledR}$ Gene Expression Master Mix (Thermo Fisher Scientific) according to the manufacturer's instructions. miRNA gene-expression assay used hsa-miR-449a as a primer and has-RNU6B as an internal control. All reactions were performed on a ViiA7 Real-Time PCR system (Thermo Fisher Scientific). The standard curve method was used to evaluate the relative expression.

Statistical analysis. Statistical analyses were carried out using JMP 10 statistical software package (SAS Institute Inc., Tokyo, Japan). Student's $t$-test was used for comparison of continuous variables. The chi-square test was used to analyze the relationship between $m i R-449 a$ expression and clinicopathological characteristics. OS and DFS were plotted by the Kaplan-Meier method and analyzed by the log-rank test to calculate differences between the curves. Differences with a $p$-value of less than 0.05 were considered to be statistically significant.

\section{Results}

HDACl as a potential target of miR-449a. In this study, HDAC1 was selected as a candidate target gene of $m i R-449 a$ and its protein expression was investigated. Figure 1 shows representative images of negative and positive expression of HDAC1. Out of 72 samples of primary CRC, 39 samples (54.2\%) were evaluated as HDAC1-positive. The rate of HDAC1 positivity was compared between the patients according to expression of miR-449a. The proportion of patients with HDAC1 positivity was significantly higher in the group with low miR-449a expression compared to that with high expression (72.2 vs. $36.1 \%, p<0.05)$.

Clinicopathological analysis of patients according to expression of miR-449a. Patients were divided into two groups by the median value of the miR-449a expression level (Table I). There was no difference in age, gender, tumor location, rate of lymph node metastasis, or CA19-9 level. Patients with a low expression of miR-449a had significantly larger and more invasive tumors compared to those with a high expression of miR-449a. Lymphovascular invasion and an elevated CEA level were significantly more frequent in the group with low miR-449a expression $(p<0.05)$.

Follow-up periods were updated from the previous reports (11). Patients with a low $m i R-449 a$ expression tended to have worse OS $(p=0.09)$ and had a significantly poorer DFS compared to patients with high expression of miR-449a $(p<0.05)$ (Figure 2). The univariate analysis showed that vascular invasion, elevated level of CA19-9 and a low expression of $m i R-449 a$ were associated with significantly 

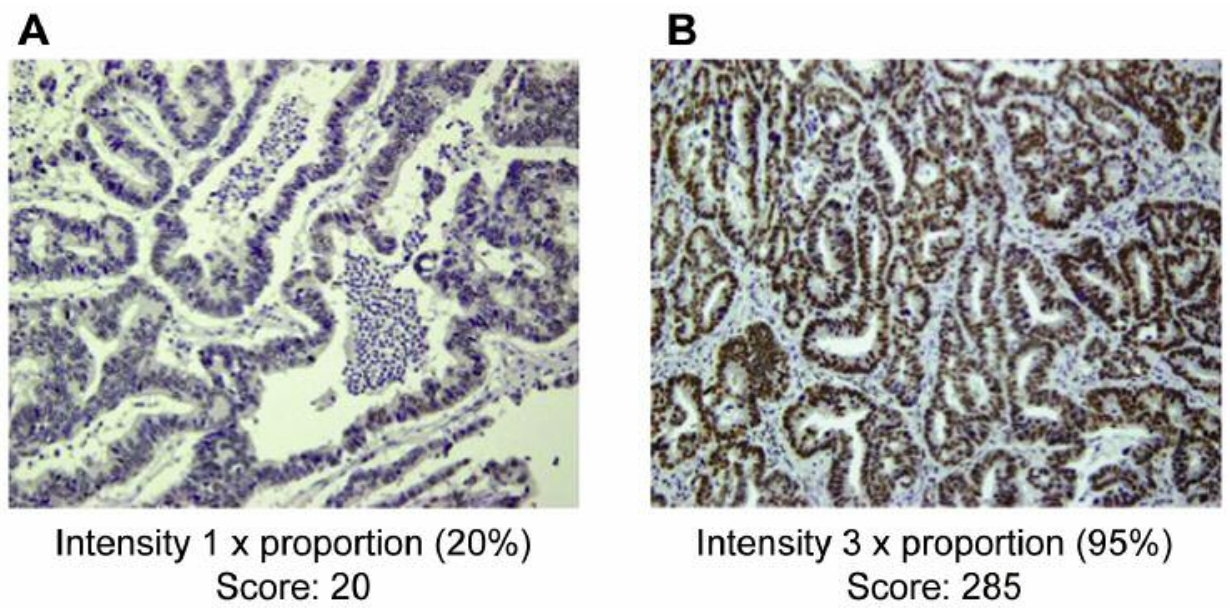

Figure 1. Immunostaining of histone deacetylase 1 in primary colorectal cancer. Representative images of negative $(A)$ and positive (B) expression. The score was calculated by multiplying the intensity of the staining and the percentage of the stained area in the tumor tissue.

Table I. Clinicopathological characteristics in patients according to expression of miR-449a.

\begin{tabular}{|c|c|c|c|c|}
\hline \multirow[b]{2}{*}{ Factor } & & \multicolumn{2}{|c|}{$m i R-449 a$ expression } & \multirow[b]{2}{*}{$p$-Value } \\
\hline & & Low $(n=36)$ & High $(n=36)$ & \\
\hline Age, years & Mean \pm SD & $66.1 \pm 9.5$ & $66.8 \pm 11.1$ & 0.78 \\
\hline Gender, $\mathrm{n}$ & Male/female & $26 / 10$ & $24 / 12$ & 0.61 \\
\hline Location, $\mathrm{n}$ & Right/left/rectum & $15 / 19 / 2$ & $14 / 17 / 5$ & 0.49 \\
\hline Size, $\mathrm{cm}$ & Mean \pm SD & $47.4 \pm 21.7$ & $36.9 \pm 18.7$ & $<0.05$ \\
\hline Depth, n & M, SM/MP, SS/SE, SI & $4 / 25 / 7$ & $16 / 12 / 8$ & $<0.05$ \\
\hline Differentiation, $\mathrm{n}$ & tub1/tub2/poor & $8 / 25 / 3$ & $18 / 18 / 0$ & $<0.05$ \\
\hline ly, n & $-1+$ & $13 / 23$ & $25 / 11$ & $<0.05$ \\
\hline $\mathrm{v}, \mathrm{n}$ & $-1+$ & $11 / 25$ & $20 / 16$ & $<0.05$ \\
\hline LN metastasis, $\mathrm{n}$ & $-/+$ & $15 / 21$ & $21 / 15$ & 0.16 \\
\hline CEA & $</ \geq 5 \mathrm{ng} / \mathrm{ml}$ & $20 / 16$ & $30 / 6$ & $<0.05$ \\
\hline CA19-9 & $</ \geq 38 \mathrm{ng} / \mathrm{ml}$ & $23 / 13$ & $29 / 7$ & 0.11 \\
\hline
\end{tabular}

ly: Lymphatic invasion; v: vascular invasion; LN: 1ymph node; CEA: carcinoembryonic antigen CA19-9: carbohydrate antigen 19-9; M: mucosa; SM: submucosa; SS: subserosa; SE: serosa; SI: serosal invasion; tub1: well-differentiated tubular adenocarcinoma; tub2: moderately differentiated tubular adenocarcinoma; poor: poorly differentiated adenocarcinoma.

poorer DFS (Table II). These three factors were investigated in multivariate analysis, which demonstrated that each was an independent prognostic factor (Table III). Taken together, these results suggest that a low expression of $m i R-449 a$ in primary $\mathrm{CRC}$ was correlated with higher tumor malignancy and poorer prognosis.

miR-449a expression in primary CRC and CRLM. The expression of $m i R-449 a$ was compared between primary CRC and patient-matched CRLM. As shown in Figure 3, the expression of $m i R-449 a$ was significantly lower in the CRLMs compared to the CRCs $(p<0.05)$. In three of the liver tumors, $m i R-449 a$ was slightly more highly expressed compared to the primary tumors and in the other 13 pairs the level of $m i R-449 a$ was lower in the CRLM.

\section{Discussion}

In this study, the expression pattern and the role of $m i R-449 a$ were demonstrated. It revealed a low expression of $m i R-449 a$ to be associated with more advanced cancer characteristics such as larger tumor size, a more pathologically invasive phenotype, the presence of lymphovascular invasion, and an increased level of serum CEA. In a previous study, miR-449a 

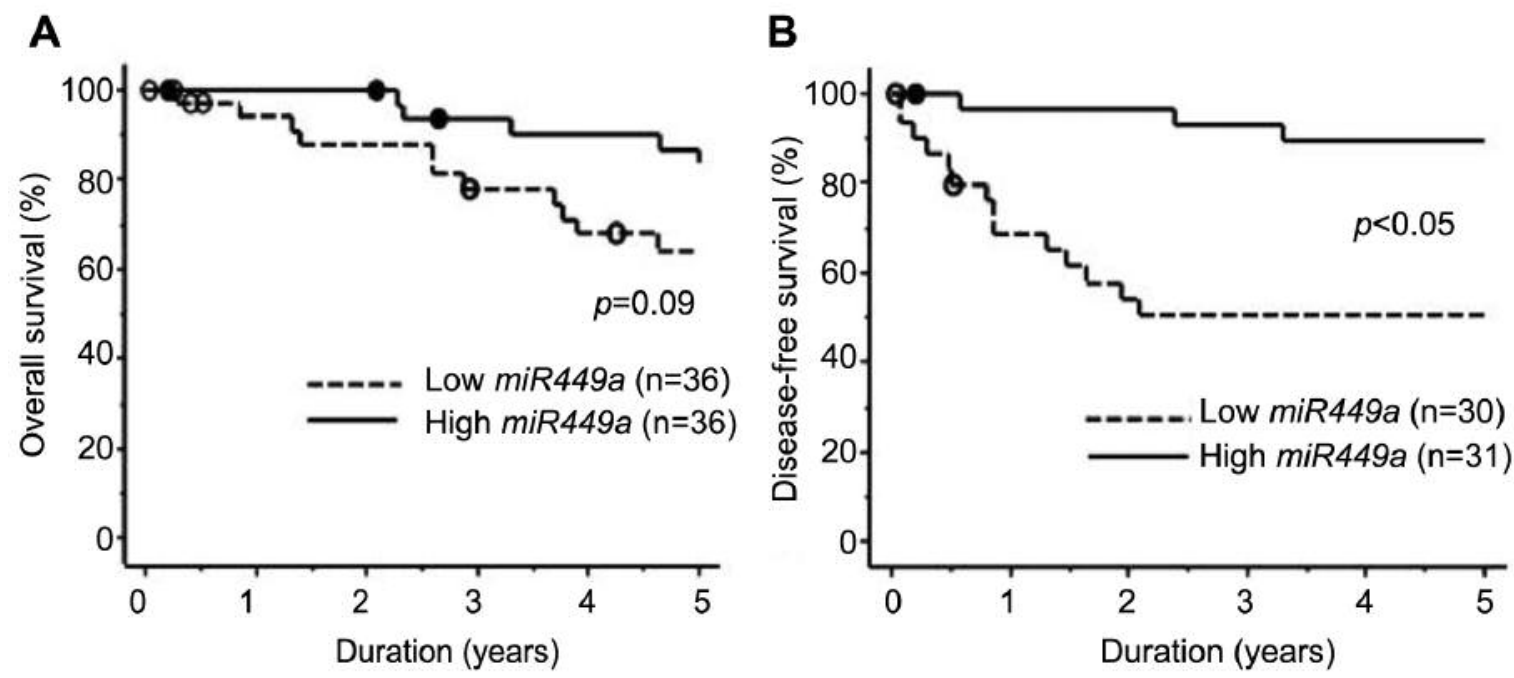

Figure 2. Overall (A) survival and disease-free (B) survival of patients according to expression of miR-449a. Patients with low expression of miR449 a tended to have worse overall survival and have significantly worse disease-free survival.

Table II. Univariate analysis of 5-year disease-free survival (DFS).

\begin{tabular}{llcc}
\hline & & 5-Year DFS $(\%)$ & $p$-Value \\
\hline Age & $<70 v s . \geq 70$ Years & $80.0 v s .59 .7$ & 0.16 \\
Gender & Male vs. female & $68.8 v s .72 .9$ & 0.81 \\
Location & Right $v s$. left & 64.6 vs. 72.9 & 0.60 \\
Differentiation & tub1 vs. tub2, poor & $64.2 v s .73 .4$ & 0.72 \\
LN metastasis & $-v s .+$ & 83.1 vs. 61.9 & 0.24 \\
ly & $-v s .+$ & $80.0 v s .59 .2$ & 0.21 \\
v & $-v s .+$ & $91.7 v s .54 .2$ & $<0.05$ \\
CEA & $<5 v s . \geq 5 \mathrm{ng} / \mathrm{ml}$ & $74.2 v s .53 .6$ & 0.17 \\
CA19-9 & $<38 v s . \geq 38 \mathrm{ng} / \mathrm{ml}$ & $78.4 v s .37 .5$ & $<0.05$ \\
$m i R-449 a$ & Low $v s$. high & $53.8 v s .86 .2$ & $<0.05$ \\
\hline
\end{tabular}

tub1: Well-differentiated tubular adenocarcinoma; tub2: moderately differentiated tubular adenocarcinoma; poor: poorly differentiated adenocarcinoma; LN: lymph node, ly: lymphatic invasion, v: vascular invasion, CEA: carcinoembryonic antigen CA19-9: carbohydrate antigen 19-9.

expression in colon cancer tissue was found to be inversely correlated with the level of serum CEA (15), supporting the findings of this study.

The expression of $m i R-449 a$ is frequently reduced in malignant tumors, including gastric and bladder cancer (16, 17). In these cancer types, $m i R-449 a$ may inhibit cell growth or induce senescence and apoptosis by activating the p53 pathway. With a follow-up period updated from the previous study, this study has also demonstrated the significance of $m i R-449 a$ as a prognostic indicator in patients with CRC. In the patients with a low expression of $m i R-449 a$, the DFS was significantly worse than for those with a high expression of $m i R-449 a$, while the same tendency was evident in patients'

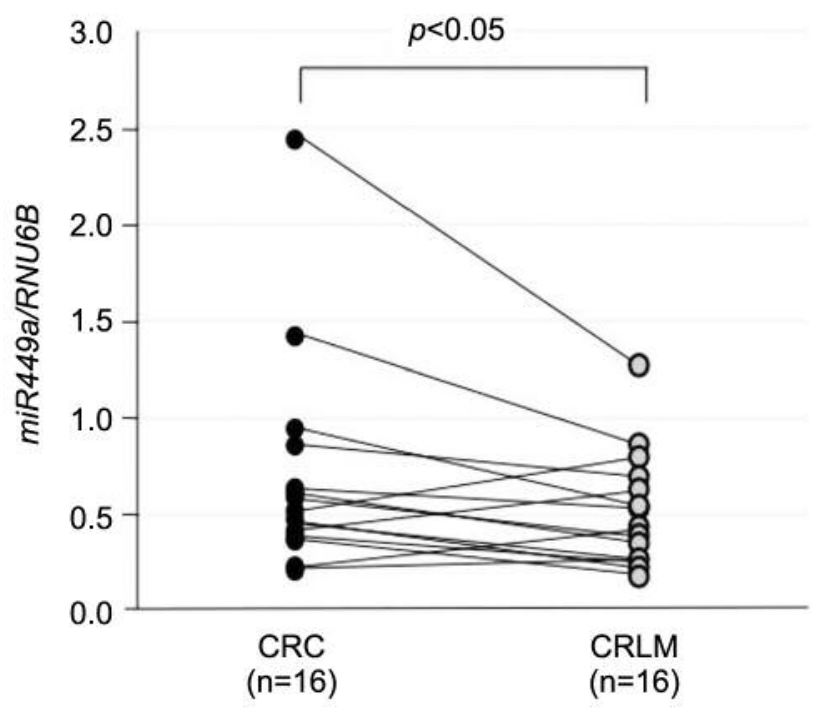

Figure 3. Comparison of miR-449a expression between primary colorectal cancer (CRC) and matched metastatic liver tumor (CRLM).

Table III. Multivariate analysis of 5-year disease-free survival.

\begin{tabular}{lccc}
\hline Factor & HR & $95 \% \mathrm{CI}$ & $p$-Value \\
\hline $\mathrm{v}+$ & 29.4 & $3.2-50.0$ & 0.018 \\
CA19-9 $\geq 38 \mathrm{ng} / \mathrm{ml}$ & 20.0 & $2.08-200.0$ & 0.001 \\
Low $m i R-449 a$ & 12.4 & $1.25-122.2$ & 0.031 \\
\hline
\end{tabular}

V+: Vascular invasion present; CA19-9: carbohydrate antigen 19-9; CI: confidence intervaI; HR: hazard ratio. 
OS. In addition, $m i R-449 a$ was selected by multivariate analysis as an independent prognostic indicator of 5-year DFS. Previous reports also revealed that low expression of miR-449a would be a useful biomarker of bladder cancer, prostate cancer, and medulloblastoma (18-21).

In previous reports using knockdown of $m i R-449 a$ in mice, the lack of miR-449a was shown to contribute to the tumorigenesis of CRC and $m i R-449 a$ regulated some possible candidates such as multL homolog 1 (MLH1) and kirsten rat sarcoma viral oncogene homolog (KRAS) (11). Other reports demonstrated that $m i R-449 a$ down-regulated oncogenes such as $H D A C 1$, transforming growth factor- $\beta(T G F B)$, special ATrich sequence-binding protein 2 (SATB2), a disintegrin and metalloproteinase domain-containing protein 10 (ADAM10), $M Y C$ and mitogen-activated protein kinase 1 (MAPK1) (1-4, $17,20)$. Interestingly, Buurman et al. reported that HDAC1 regulated $m i R-449 a$ expression (17), suggesting a negative feedback loop between $m i R-449 a$ and $H D A C 1$. Targetscan 7.0 and miRanda (http://www.microrna.org/microrna/home.do) also predict $H D A C l$ as a possible target gene with strong capability from the basal sequences data. We previously demonstrated the role of HDAC1 in intrahepatic cholangiocarcinoma (13) and selected HDAC for further study of $m i R-449 a$. In the present study, the expression of HDAC1 in CRC tissue was inversely correlated with $m i R$ $449 a$ expression. This inverse correlation suggests that HDAC in primary colorectal tumor was transcriptionally or post-transcriptionally regulated by $m i R-449 a$ as a target gene. Furthermore, this study found $m i R-449 a$ expression was lower in metastatic liver tumor compared to primary colorectal tumor, suggesting the possibility of change to a more advanced phenotype in metastatic tumors. The expression of HDAC1, on the contrary, was higher in metastatic liver tumor, supporting the hypothesis that the HDAC1 is an important target gene of $m i R-449 a$ in clinical settings. As far as we are aware, there was no previous report comparing the expression pattern of $m i R-449 a$ and its target genes in primary tumor and metastatic lesions, which is to be further investigated in future study.

The limitation of this study is shortage of the number of samples and the lack of detailed in vitro or in vivo analyses to determine the role of $m i R-449 a$ in regulating HDAC1 expression. Further detailed examination is needed to confirm the descriptive data presented in this study.

In conclusion, the results of this study suggest that a low expression of $m i R-449 a$ could be a useful prognostic indicator for patients with CRC. miR-449a might regulate HDAC1 expression in both primary CRC and CRLM.

\section{Conflicts of Interest}

None of the Authors has any potential financial conflicts of interest related to this study.

\section{Authors' Contributions}

Ishikawa $\mathrm{D}$ designed and carried out the experiment and wrote the initial draft of the article. Takasu $\mathrm{C}$ and Yoshikawa $\mathrm{K}$ contributed to analysis and interpretation of data. Tokunaga $\mathrm{T}$ and Higashijima $\mathrm{J}$ contributed to data collection and interpretation. Kashihara $\mathrm{H}$ and Nishi $M$ assisted in the preparation of the article. Shimada $M$ and Yasutomo K supervised the project. All Authors have critically reviewed the manuscript, approved the final version of the article.

\section{References}

1 Noonan EJ, Place RF, Pookot D, Basak S, Whitson JM, Hirata H, Giardina C and Dahiya R: Mir-449a targets hdac-1 and induces growth arrest in prostate cancer. Oncogene 28(14): 1714-1724, 2009. PMID. DOI: 10.1038/onc.2009.19

2 Yang X, Feng M, Jiang X, Wu Z, Li Z, Aau M and Yu Q: Mir$449 \mathrm{a}$ and mir-449b are direct transcriptional targets of e2f 1 and negatively regulate prb-e $2 \mathrm{f} 1$ activity through a feedback loop by targeting cdk6 and cdc25a. Genes Dev 23(20): 2388-2393, 2009. PMID: 2764491. DOI: 10.1101/gad.1819009

3 Lize M, Pilarski S and Dobbelstein M: E2f1-inducible microrna $449 \mathrm{a} / \mathrm{b}$ suppresses cell proliferation and promotes apoptosis. Cell Death Differ 17(3): 452-458, 2010. PMID: 19960022. DOI: 10.1038/cdd.2009.188

4 Luo W, Huang B, Li Z, Li H, Sun L, Zhang Q, Qiu X and Wang E: Microrna-449a is downregulated in non-small cell lung cancer and inhibits migration and invasion by targeting c-met. PLoS One 8(5): e64759, 2013. PMID: 3667122. DOI: 10.1371/ journal.pone.0064759

5 Wang $\mathrm{Z}$ and Burke PA: The role of micrornas in hepatocyte nuclear factor-4alpha expression and transactivation. Biochim Biophys Acta 1829(5): 436-442, 2013. PMID: 23298640. DOI: 10.1016/j.bbagrm.2012.12.009

6 Ramamoorthy A, Li L, Gaedigk A, Bradford LD, Benson EA, Flockhart DA and Skaar TC: In silico and in vitro identification of micrornas that regulate hepatic nuclear factor 4alpha expression. Drug Metab Dispos 40(4): 726-733, 2012. PMID: 3310421. DOI: 10.1124/dmd.111.040329

7 Hoesel B, Bhujabal Z, Przemeck GK, Kurz-Drexler A, Weisenhorn DM, Angelis MH and Beckers J: Combination of in silico and in situ hybridisation approaches to identify potential dll1 associated mirnas during mouse embryogenesis. Gene Expr Patterns 10(6): 265-273, 2010. PMID: 20558326. DOI: 10.1016/ j.gep.2010.06.002

8 Halappanavar S, Jackson P, Williams A, Jensen KA, Hougaard KS, Vogel U, Yauk CL and Wallin H: Pulmonary response to surface-coated nanotitanium dioxide particles includes induction of acute phase response genes, inflammatory cascades, and changes in micrornas: A toxicogenomic study. Environ Mol Mutagen 52(6): 425-439, 2011. PMID: 3210826. DOI: 10.1002/ em.20639

9 Jeon HS, Lee SY, Lee EJ, Yun SC, Cha EJ, Choi E, Na MJ, Park JY, Kang J and Son JW: Combining microrna-449a/b with a hdac inhibitor has a synergistic effect on growth arrest in lung cancer. Lung Cancer 76(2): 171-176, 2012. PMID: 22078727. DOI: $10.1016 /$ j.lungcan.2011.10.012

10 Bao J, Li D, Wang L, Wu J, Hu Y, Wang Z, Chen Y, Cao X, Jiang C, Yan W and Xu C: Microrna-449 and microrna-34b/c function redundantly in murine testes by targeting $\mathrm{e} 2 \mathrm{f}$ 
transcription factor-retinoblastoma protein (e2f-prb) pathway. J Biol Chem 287(26): 21686-21698, 2012. PMID: 3381132. DOI: 10.1074/jbc.M111.328054

11 Niki M, Nakajima K, Ishikawa D, Nishida J, Ishifune C, Tsukumo SI, Shimada M, Nagahiro S, Mitamura Y and Yasutomo K: Microrna-449a deficiency promotes colon carcinogenesis. Sci Rep 7(1): 10696, 2017. PMID: 5587792. DOI: $10.1038 / \mathrm{s} 41598-017-10500-0$

12 Glozak MA and Seto E: Histone deacetylases and cancer. Oncogene 26(37): 5420-5432, 2007. PMID: 17694083. DOI: 10.1038/sj.onc. 1210610

13 Morine Y, Shimada M, Iwahashi S, Utsunomiya T, Imura S, Ikemoto T, Mori H, Hanaoka J and Miyake H: Role of histone deacetylase expression in intrahepatic cholangiocarcinoma. Surgery 151(3): 412-419, 2012. PMID: 21982637. DOI: 10.1016/j.surg.2011.07.038

14 Werner J, Fritz S and Buchler MW: Intraductal papillary mucinous neoplasms of the pancreas--a surgical disease. Nat Rev Gastroenterol Hepatol 9(5): 253-259, 2012. PMID: 22392299. DOI: $10.1038 /$ nrgastro.2012.31

15 Chen H, Lin YW, Mao YQ, Wu J, Liu YF, Zheng XY and Xie LP: MicroRNA-449a acts as a tumor suppressor in human bladder cancer through the regulation of pocket proteins. Cancer Lett 320(1): 40-47, 2012. PMID: 22266187. DOI: 10.1016/ j.canlet.2012.01.027

16 Lai CY, Yu SL, Hsieh MH, Chen CH, Chen HY, Wen CC, Huang YH, Hsiao PC, Hsiao CK, Liu CM, Yang PC, Hwu HG and Chen WJ: Microrna expression aberration as potential peripheral blood biomarkers for schizophrenia. PLoS One 6(6): e21635, 2011. PMID: 3126851. DOI: 10.1371/journal.pone.0021635
17 Buurman R, Gurlevik E, Schaffer V, Eilers M, Sandbothe M, Kreipe H, Wilkens L, Schlegelberger B, Kuhnel F and Skawran B: Histone deacetylases activate hepatocyte growth factor signaling by repressing microrna-449 in hepatocellular carcinoma cells. Gastroenterology 143(3): 811-820 e811-815, 2012. PMID: 22641068. DOI: 10.1053/j.gastro.2012.05.033

18 Jukic DM, Rao UN, Kelly L, Skaf JS, Drogowski LM, Kirkwood JM and Panelli MC: Microrna profiling analysis of differences between the melanoma of young adults and older adults. J Transl Med 8: 27, 2010. PMID: 2855523. DOI: 10.1186/1479-5876-8-27

19 Marcet B, Chevalier B, Luxardi G, Coraux C, Zaragosi LE, Cibois M, Robbe-Sermesant K, Jolly T, Cardinaud B, Moreilhon C, Giovannini-Chami L, Nawrocki-Raby B, Birembaut P, Waldmann R, Kodjabachian L and Barbry P: Control of vertebrate multiciliogenesis by mir-449 through direct repression of the delta/notch pathway. Nat Cell Biol 13(6): 693-699, 2011. PMID: 21602795. DOI: $10.1038 / \mathrm{ncb} 2241$

20 Bou Kheir T, Futoma-Kazmierczak E, Jacobsen A, Krogh A, Bardram L, Hother C, Gronbaek K, Federspiel B, Lund AH and Friis-Hansen L: Mir-449 inhibits cell proliferation and is downregulated in gastric cancer. Mol Cancer 10: 29, 2011. PMID: 3070685. DOI: 10.1186/1476-4598-10-29

21 Rudolf E, John S and Cervinka M: Irinotecan induces senescence and apoptosis in colonic cells in vitro. Toxicol Lett 214(1): 1-8, 2012. PMID: 22898888. DOI: 10.1016/j.toxlet.2012.08.004

Received January 21, 2019

Revised May 18, 2019

Accepted May 22, 2019 